\title{
Rheological and structural properties of Hemiramphus far skin gelatin: Potential use as an active fish coating agent
}

\author{
Ola Abdelhedi ${ }^{a}$, Mourad Jridi ${ }^{a}$,*, Rim Nasri ${ }^{a}$, Leticia Mora ${ }^{\mathrm{b}}$, Fidel Toldráb ${ }^{\mathrm{b}}$ Moncef Nasri $^{\mathrm{a}}$

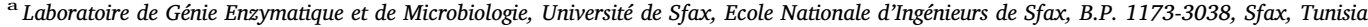 \\ ${ }^{\mathrm{b}}$ Instituto de Agroquímica y Tecnología de Alimentos (CSIC), Avenue Agustín Escardino 7, 46980, Paterna (Valencia), Spain
}

\begin{abstract}
A B S T R A C T
The present study aims to characterize black-barred (Hemiramphus far) skin gelatin (BG) gel enriched or not with its hydrolysate (BGH) in terms of their rheological and micro-structural properties, as well as to evaluate their effect on smooth hound fillet quality during chilled storage. The results of the rheological properties showed that peptides addition influenced elastic and loss modulus as observed from temperature sweep. Based on the microstructure, BG gel had a fine network with small voids that were filled by the presence of BGH peptides. On the other hand, when used as coating agents for smooth hound fillets, BG and BG-BGH showed that, in comparison to control group, fish spoilage was significantly delayed in coated samples. In fact, after 8 days of storage, samples coated with BG and BG + BGH showed the lowest weight loss levels, and preserved their initial water activity $\left(a_{w}\right)$ values. In addition, fillet coating was able to significantly reduce TVB-N content and oxidation process, as reflected by the low malondialdehyde and carbonyl contents. Furthermore, compared to the control group, all the treatments were found to reduce the degree of microbial deterioration of the fillets, leading to low the free amino acids and nucleotides contents in wrapped fish samples. Therefore, gelatin coating helps to prevent fish fillets from deterioration and oxidation processes.
\end{abstract}

\section{Introduction}

Fish gelatin is a protein obtained by partial hydrolysis and thermal denaturation of fish collagen (Jridi, Lassoued, Nasri, Ayadi \& Nasri, 2014). Gelatins from various marine raw materials generally have different rheological and structural properties (Sinthusamran, Benjakul, Swedlund, \& Hemar, 2017), which are directly related to their biochemical characteristics such as amino acid composition and molecular weight, etc. (Jridi, Lassoued, Nasri, Ayadi \& Nasri, 2014). Gelatin has a wide range of applications, in pharmaceutical and cosmetic industries, as food additive, biopolymer, and photographic agent (Das, Suguna, Prasad, Vijaylakshmi, \& Renuka, 2017). In addition, gelatin is known by its film-forming capacity giving transparent films, which make it an excellent edible film component that can fulfill commercial packaging needs (Arvanitoyannis, 2002; Hosseini \& Gómez-Guillén, 2018). Gelatin-based packaging film may be also used as a carrier of antimicrobial and/or antioxidant agents (Benbettaïeb, Karbowiak, \& Debeaufort, 2017), in order to improve the quality and the shelf life of packaged foods.

The stability of fresh fish fillets during chilled storage is used to be perishable after a limited period of time. In fact, fresh fish products are very sensitive due to the presence of huge number of factors that can cause their deterioration including neutral $\mathrm{pH}$, high water activity, presence of endogenous autolytic enzymes, and the high content in proteins and unsaturated fatty acids (Duan, Jiang, Wang, Yu, \& Wang, 2011). Spoilage bacteria causing-sensory deterioration, lipid and protein oxidation and nucleotides degradation are the most common problems that usually affect the quality of fresh seafood products.

The increasing demand for fresh chilled fish with an extended shelf life has intensified the search of technologies that support fresh fish quality. One of the main developments is the modification of the atmosphere packaging (Viji et al., 2016), or the use of edible coatings (Fan et al., 2009; Jian, Wenyi, \& Wuyong, 2011) and active bio-based packaging (Heydari, Alemzadeh, \& Vossoughi, 2013). Gelatin edible coating can act as a barrier to the permeability of oxygen and, thereby it can reduce the oxidation reactions and food products deterioration. Numerous studies have been focused on using edible coatings to preserve food quality (De Oliveira \& Silva, 2017; Soares, Mendes, \& Vicente, 2013). Gelatin properties, such as non-toxicity, biocompatibility, and biodegradability increased its use in food processing 
industries. In fact, gelatin coatings have been found to decrease moisture loss and control oxidation during chilled storage (Feng, Bansal, \& Yang, 2016).

Unlike conventional edible coating technique, bioactive packaging is considered a very promising technique for shelf-life extending of food products (Hosseini \& Gómez-Guillén, 2018). In fact, gelatin matrix allows controlling the release of the bioactive substances from the packaging film to the coated food during the storage period and thereby slowing down the deterioration of food products. Bioactive peptides from collagen and gelatin with biological properties have become a topic of great interest for healthy food and processing/preservation industries. For instance, gelatin hydrolysates from tuna and squid skin gelatins were found to be potential antibacterial agents (Gómez-Guillén et al., 2010). Furthermore, gelatin hydrolysates from thornback ray (Raja clavata) skin (Lassoued et al., 2015), cuttelfish (Sepia officinalis) skin (Jridi, Lassoued, Nasri, Ayadi \& Nasri, 2014) and giant squid (Dosidiscus gigas) tunics (Alemán et al., 2011) have been reported to exhibit antioxidant activity.

Black-barred halfbeak (Hemiramphus far) is among the actinopterygii fish species, which are geographically widespread and numerically abundant around the world, besides their low market value. So, the utilization of halfbeak species for bioactive molecules extraction could be a good way for their valorization. In our previous study, $H$. far skin had been used to extract gelatin and bioactive gelatin peptides with antioxidant and antibacterial properties (Abdelhedi et al., 2017). Limited studies have been conducted on the utilization of gelatin gels containing gelatin hydrolysate as bioactive agent for maintaining fish quality and safety. Therefore, the purpose of this study is to evaluate the effect of black-barred halfbeak gelatin (BG) coating enriched with its hydrolysate (BGH) in preserving the quality of fresh fish fillets during 8 days of cold storage. Particularly, weight loss, color evolution, lipid oxidation, carbonyl content, total volatile basic nitrogen (TVB-N) content, free amino acids and nucleotides degradation as well as microbial counts of coated and uncoated fish samples were determined during 8 days of storage. These parameters were studied in order to evaluate the specific effect of gelatin coating.

\section{Materials and methods}

\subsection{Raw material preparation}

Black-barred halfbeak (Hemiramphus far) skin was obtained from fish market located in Sfax City, Tunisia. The samples were packed in polyethylene bags, placed in ice and immediately transported to the laboratory. The skin was washed with tap water to eliminate pigments and then stored in sealed plastic bags at $-20^{\circ} \mathrm{C}$ until use for gelatin extraction.

\subsection{Gelatin extraction and hydrolysate preparation}

The gelatin extraction procedure was performed as previously detailed in Abdelhedi et al. (2017). After freeze-drying, the obtained powder, referred as black-barred halfbeak gelatin (BG), was stored at $4{ }^{\circ} \mathrm{C}$ until use.

BG powder was dissolved in distilled water (2\%; w/v) and subjected to enzymatic hydrolysis using Purafect ${ }^{\circ}$ with an enzyme/substrate ratio of $30 / 1(\mathrm{U} / \mathrm{mg})\left(\mathrm{pH} 10.0,50^{\circ} \mathrm{C}\right)$. The gelatin solutions were allowed to equilibrate for $30 \mathrm{~min}$ before hydrolysis were initiated. During the reaction, the $\mathrm{pH}$ of the mixture was maintained constant by continuous addition of $2 \mathrm{M} \mathrm{NaOH}$ solution. Finally, the hydrolysate mixtures were centrifuged at $8000 \times \mathrm{g}$ for $20 \mathrm{~min}$ and the soluble fraction was freezedried and stored at $-20^{\circ} \mathrm{C}$ for further use. The degree of gelatin hydrolysis (DH) was determined according to Adler-Nissan (1986, pp. 57-131). The obtained powder after freeze-drying was referred as black-barred halfbeak gelatin hydrolysate (BGH).

\subsection{Gelatin gel characterization}

\subsubsection{Scanning electron microscopy}

Gelatin-based gel microstructure was visualized using a scanning electron microscope (SEM, Cambridge Scan-360 microscope) at an accelerating voltage of $3.0 \mathrm{kV}$, as previously described by Jridi et al. (2015). The sample was frozen under liquid nitrogen. Prior to visualization, sample was mounted on brass stub and sputtered with gold in order to make the sample conductive. Samples were photographed with an angle of $90^{\circ}$ to the surface to allow observation of the films cross section. Photos were taken at 1000 and 3000 magnifications.

\subsubsection{Viscoelastic properties}

Dynamic studies were performed on an AR1000 Rheometer (Physica MCR-301, Anton Paar, Germany) using a cone-plate geometry (cone angle $2^{\circ}$ ), as previously detailed in Abdelhedi et al. (2017). The viscosity measurement was performed at a scan rate of $1{ }^{\circ} \mathrm{C} / \mathrm{min}$, frequency $1 \mathrm{~Hz}$, oscillating applied stress of $3.0 \mathrm{~Pa}$ and gap $0.15 \mathrm{~mm}$. During the experience, the gel was heated from 5 to $50{ }^{\circ} \mathrm{C}$, cooled from 50 to $5{ }^{\circ} \mathrm{C}$ and then kept at $5{ }^{\circ} \mathrm{C}$ for $10 \mathrm{~min}$. The $\tan \delta$ was calculated from the ratio of G' and G" obtained from temperature sweep tests.

\subsection{Characterization of coated of smooth hound fillets}

\subsubsection{Coating preparation}

Fresh smooth hound fillets, with an average weight of 1000-1200 g each, were obtained after removing the head, bone, skin and viscera, from the local fish market (Sfax City, Tunisia). Fillets were then cut into pieces with dimensions of $10 \mathrm{~cm} \times 5 \mathrm{~cm} \times 2 \mathrm{~cm}$ (length $\mathrm{x}$ width $\mathrm{x}$ height), divided into four groups, with 50 pieces in each, and immediately coated. Bovine commercial gelatin (CG) was used as control. CG and BG coating solutions were prepared by mixing $4 \mathrm{~g}$ of each dried gelatin in $100 \mathrm{ml}$ of distilled water at $40{ }^{\circ} \mathrm{C}$ for $30 \mathrm{~min}$. In parallel, the gelatin hydrolysate was dissolved in black-barred halfbeak gelatin solution at $1 \mathrm{mg} / \mathrm{ml}$ to prepare active gelatin solution. Fish samples were assigned into four treatment groups, consisting of non coated control samples (C), samples coated with bovine commercial gelatin solution for $30 \mathrm{~s}$ (CG), samples dipped into black barred halfbeak gelatin solution during $30 \mathrm{~s}$ (BG) and samples dipped, for $30 \mathrm{~s}$ also, into BG solution enriched with gelatin hydrolysate (BG + BGH).

After treatment, all samples were weighed and stored at $4{ }^{\circ} \mathrm{C}$ without further external packaging (overwrap) to accentuate oxidation process in simulated fresh conditions. Groups were sampled at $0,3,6$ and 8 days of storage for physicochemical and microbial analysis.

\subsubsection{Weight loss}

The weight loss of the fish samples on days 3, 6 and 8 was calculated using the following equation, according to Sathivel (2005):

Weight loss $(\%)=[(\mathrm{W} 0-\mathrm{Wi}) / \mathrm{W} 0] \times 100$

where $\mathrm{W}_{0}$ is the initial weight of sample (day 0 ) and $\mathrm{W}_{\mathrm{i}}$ is the weight of the same sample after 3,6 and 8 days of chilled storage.

\subsubsection{Color, $p H$ and water activity measurements}

The color of fish samples was determined using a CR-410 colorimeter (Minolta Chroma Meter Measuring Head, Osaka, Japan) with D65 illuminant. The instrument was standardized using a standard white plate. An average value of color was determined by taking observations from three different fish samples from each group on days 0 , 3,6 and 8 of storage. CIE lightness $\left(\mathrm{L}^{*}\right)$, redness ( $\left.\mathrm{a}^{*}\right)$ and yellowness $\left(b^{*}\right)$ were recorded. Chroma $\left(C^{*}\right)$ was calculated based on the following equation:

$\mathrm{C}^{*}=\left(\mathrm{a}^{*_{2}}+\mathrm{b}^{* 2}\right)^{1 / 2}$

To measure the $\mathrm{pH}$ of fish from each group during the storage period, the fillet sample $(2 \mathrm{~g})$ was first homogenized in $20 \mathrm{ml}$ of 
bidistilled water for $2 \mathrm{~min}$. The $\mathrm{pH}$ was then measured using a $\mathrm{pH}$-meter (Hanna, 211, Mauritius).

Water activity $\left(\mathrm{a}_{\mathrm{w}}\right)$ was determined using FAst-lab water activity meter (Gbx, Romans Isère Cédex, France) at $25^{\circ} \mathrm{C}$. The equipment was previously calibrated with sodium chloride and potassium sulfate.

\subsubsection{Total volatile basic nitrogen}

The total volatile basic nitrogen (TVB-N) value was estimated by the micro-diffusion method (Abelti, 2013) following the distillation of the perchloric acid of the homogenized fish samples. The distillate was collected in a flask containing aqueous solution of boric acid and methyl red as an indicator. Afterward, the boric acid solution was titrated with sulfuric acid solution. The TVB-N value (mg N/100 g of fish) was determined according to the volume of sulfuric acid consumed for titration.

\subsubsection{Lipid per-oxidation measurement}

Thio-barbituric acid reactive substances (TBARS) of fish samples were evaluated using the method proposed by Witte, Krause and Bailey (1970). Briefly, a fish sample ( $5 \mathrm{~g}$ ) was dispersed in $5 \%$ trichloroacetic acid solution $(20 \mathrm{ml})$ and homogenized in a Polytron homogenizer (PT 2100, Kinematica AG, Switzerland) for $5 \mathrm{~min}$. The homogenate was centrifuged at $10,000 \times \mathrm{g}$ for $10 \mathrm{~min}$ at $4{ }^{\circ} \mathrm{C}$. The supernatant $(4 \mathrm{ml})$ was reacted with $0.8 \mathrm{ml}$ of chlorhydric acid $(\mathrm{HCl} 0.6 \mathrm{M})$ and $3.2 \mathrm{ml}$ of tris-thiobarbituric acid (TBA) solution (Tris $26 \mathrm{mM}$, TBA $120 \mathrm{mM}$ ) and then incubated in a water bath at $85{ }^{\circ} \mathrm{C}$ for $10 \mathrm{~min}$. The absorbance of each mixture was measured at $532 \mathrm{~nm}$. TBARS values were calculated from a standard curve of malonaldehyde (MDA) and expressed as mg of $\mathrm{MDA} / \mathrm{kg}$ of fish sample.

The lipid oxidation was as well evaluated by the conjugated diene content, as previously described by Esterbauer, Cheeseman, Dianzani, Poli, and Slater (1982).

\subsubsection{Carbonyl content}

Carbonyl content was measured using the method described by Vuorela et al. (2005). Fish sample (1 g) was homogenized with $10 \mathrm{ml}$ of $0.15 \mathrm{M}$ of potassium chloride solution $(\mathrm{KCl})$ using a Polytron homogenizer (Brinkman Inc., Westbury, NY, USA) for $60 \mathrm{~s}$. Homogenate $(100 \mu \mathrm{l})$ was then mixed with $10 \%$ trichloroacetic acid (TCA) solution and centrifuged for $5 \mathrm{~min}$ at $5000 \times \mathrm{g}$. The supernatant was removed and the pellet (bottom layer) was used for carbonyl content measurement. A volume of $1 \mathrm{ml}$ of $2 \mathrm{M} \mathrm{HCl}$ containing $0.2 \%(\mathrm{w} / \mathrm{v})$ dinitrophenyl hydrazine was thereafter added. After incubation for $1 \mathrm{~h}$ (shaken periodically), $1 \mathrm{ml} \mathrm{10 \%} \mathrm{TCA} \mathrm{was} \mathrm{added.} \mathrm{The} \mathrm{sample} \mathrm{was} \mathrm{mixed}$ and centrifuged again for $5 \mathrm{~min}$ at $5000 \times \mathrm{g}$ and the supernatant was removed without damaging the pellet. A volume of $1 \mathrm{ml}$ of ethanol/ ethyl acetate solution ( $\mathrm{v} / \mathrm{v}, 1: 1)$ was used to wash the pellet. This step was repeated twice to ensure purity. Thereafter, the pellet was dissolved in $1.5 \mathrm{ml}$ of $20 \mathrm{mM}$ sodium phosphate buffer with $6 \mathrm{M}$ guanidine hydrochloride. The solution was shaken and centrifuged for $2 \mathrm{~min}$ at $5000 \times$ g. The carbonyl content was measured by reading the absorbance of each sample at $370 \mathrm{~nm}\left(\mathrm{Abs}_{370 \mathrm{~nm}}\right)$. A bovine serum albumin solution was used to plot the standard curve for protein quantification and carbonyls $(\mu \mathrm{mol} / \mathrm{g})$ were calculated as the following:

Carbonyl content $=\mathrm{Abs}_{370 \mathrm{~nm}} / 21.0 \mathrm{mM}^{-1} \mathrm{~cm}^{-1}$

where $21.0 \mathrm{mM}^{-1} \mathrm{~cm}^{-1}$ is the molar extinction coefficient of carbonyls.

\subsubsection{Microbiological analysis}

Bacteriological counts were determined by mixing $1 \mathrm{~g}$ of fish sample in $9 \mathrm{ml}$ of $0.9 \% \mathrm{NaCl}$ solution. Decimal dilutions were prepared and plated in the appropriate media. The inoculated plates were incubated at $37^{\circ} \mathrm{C}$ for 2 days for total viable counts (TVC), and at $4{ }^{\circ} \mathrm{C}$ for 7 days for total psychrotrophilic counts (TPC). Total viable and psychrotrophilic bacterial counts were determined by the pour plate method, using plate count agar (PCA) medium. All microbial counts were converted to logarithms of colony-forming units per gram of fish sample $\left(\log _{10} \mathrm{CFU} / \mathrm{g}\right.$ ) (Nowzari, Shábanpour, \& Ojagh, 2013).

\subsubsection{Nucleotide content analysis}

The extraction and quantification of the nucleotides were carried out as described by Hernández-Cázares, Aristoy, and Toldrá (2011). $5 \mathrm{~g}$ of each sample were homogenized with $15 \mathrm{ml}$ of $0.6 \mathrm{M}$ of perchloric acid for $10 \mathrm{~min}$ at $4{ }^{\circ} \mathrm{C}$ in a Stomacher (IUL Instrument, Barcelona, Spain). The extract was centrifuged at $10,000 \times \mathrm{g}$ for $20 \mathrm{~min}$ at $4^{\circ} \mathrm{C}$ and the supernatant was filtered through glass wool. Then, $12 \mathrm{ml}$ was neutralized $(\mathrm{pH}$ 6.5) with potassium carbonate in an ice bath. The neutralized solution was centrifuged and the supernatant was used for nucleotides determination.

Nucleotides content was analyzed by reverse phase-HPLC (RPHPLC) with a 1200 Agilent liquid chromatography (Agilent Technologies, Palo Alto, CA, USA) equipped with a diode array detector. The separation was performed at $30^{\circ} \mathrm{C}$ using a Zorbax Eclipse plus C18 column $(4.6 \times 250 \mathrm{~mm}, 5 \mu \mathrm{m})$ (Agilent Technologies). The eluents used were (A) containing $0.1 \mathrm{M}$ potassium phosphate buffer $(\mathrm{pH}$ 6.0) mixed with Pic A reagent (Paired-Ion Chromatography, Waters), while (B) contained the mobile phase A: methanol mixture $(75: 25)$. The flow rate used was $1 \mathrm{ml} / \mathrm{min}$. Nucleotide peaks were identified by comparison of their retention times and spectra between 200 and $350 \mathrm{~nm}$ with those of standards (Sigma, St Louis, MO). The ratio of the area of the nucleotide peak was used as the $y$-axis variable to prepare a calibration curve and subsequently used to determine the nucleotide concentration in each sample. Results were expressed as $\mu \mathrm{mol}$ of nucleotide per $g$ of fish.

\subsubsection{Free amino acids}

Free amino acids (FAA) were analyzed according to Jurado, García, Timón and Carrapiso (2007). Five grams of the sample were homogenized with $20 \mathrm{ml}$ of $0.01 \mathrm{M} \mathrm{HCl}$ in Stomacher (IUL Instrument, Barcelona, Spain) at $4^{\circ} \mathrm{C}$ for $8 \mathrm{~min}$. The homogenate was centrifuged at $10,000 \times \mathrm{g}$ for $20 \mathrm{~min}$ at $4^{\circ} \mathrm{C}$ and supernatant was filtrated through glass-wool and served for FAA analysis. $250 \mu \mathrm{l}$ of supernatant were mixed with $50 \mu \mathrm{l}$ of internal standard, norleucine $(10 \mathrm{mM})$ and $750 \mu \mathrm{l}$ of acetonitrile. The mixture was centrifuged at $10,000 \times g$ and supernatant $(500 \mu \mathrm{l})$ was dried without heating in a centrifugal evaporator (Jouan RCT 90 cold trap). Then, $15 \mu \mathrm{l}$ of drying reagent (methanol: sodium acetate $1 \mathrm{M}$ : TEA, 2:2:1) were added to the dried samples and the mixtures were dried again. The derivatization was then carried out with phenyl isothiocyanate (PITC) by adding $15 \mu$ of PITC solution (methanol: water: TEA: PITC, 7:1:1:1). Solutions were kept at room temperature for $20 \mathrm{~min}$ and then dried again. Standard solutions $(1 \mathrm{mM})$ of amino acids (Sigma Chemical Co., USA) were similarly treated and used for amino acid identification.

Before analysis, samples and standards were reconstituted in $300 \mu 1$ of a dilution reagent solution composed of $5 \mathrm{mM}$ sodium phosphate buffer and $5 \%$ acetonitrile ( $\mathrm{pH} 7.4$ ). The PITC derivates were quantified by RP-HPLC with a 1200 Agilent liquid chromatography (Agilent Technologies, Palo Alto, CA, USA) equipped with a diode array detector, using a PicoTag column $(300 \mathrm{~mm} \times 3.9 \mathrm{~mm}$, Waters $)$. The temperature was set at $52{ }^{\circ} \mathrm{C}$ and the detection was carried out at $254 \mathrm{~nm}$. The eluents used were (A) $0.07 \mathrm{M}$ sodium acetate adjusted to pH 6.55 and containing 2.5\% acetonitrile and (B) 45:40:15 acetonitrile: water: methanol, with a flow rate of $1 \mathrm{ml} / \mathrm{min}$. Results were expressed as $\mathrm{mg}$ of each amino acid per $\mathrm{g}$ of fish fillet sample.

\subsection{Statistical analysis}

Results were expressed in mean \pm SEM (Standard Error Mean) and analyzed using the statistical software SPSS ver. 18.0, professional edition. A one-way and two-way analysis of variance (ANOVA) was 

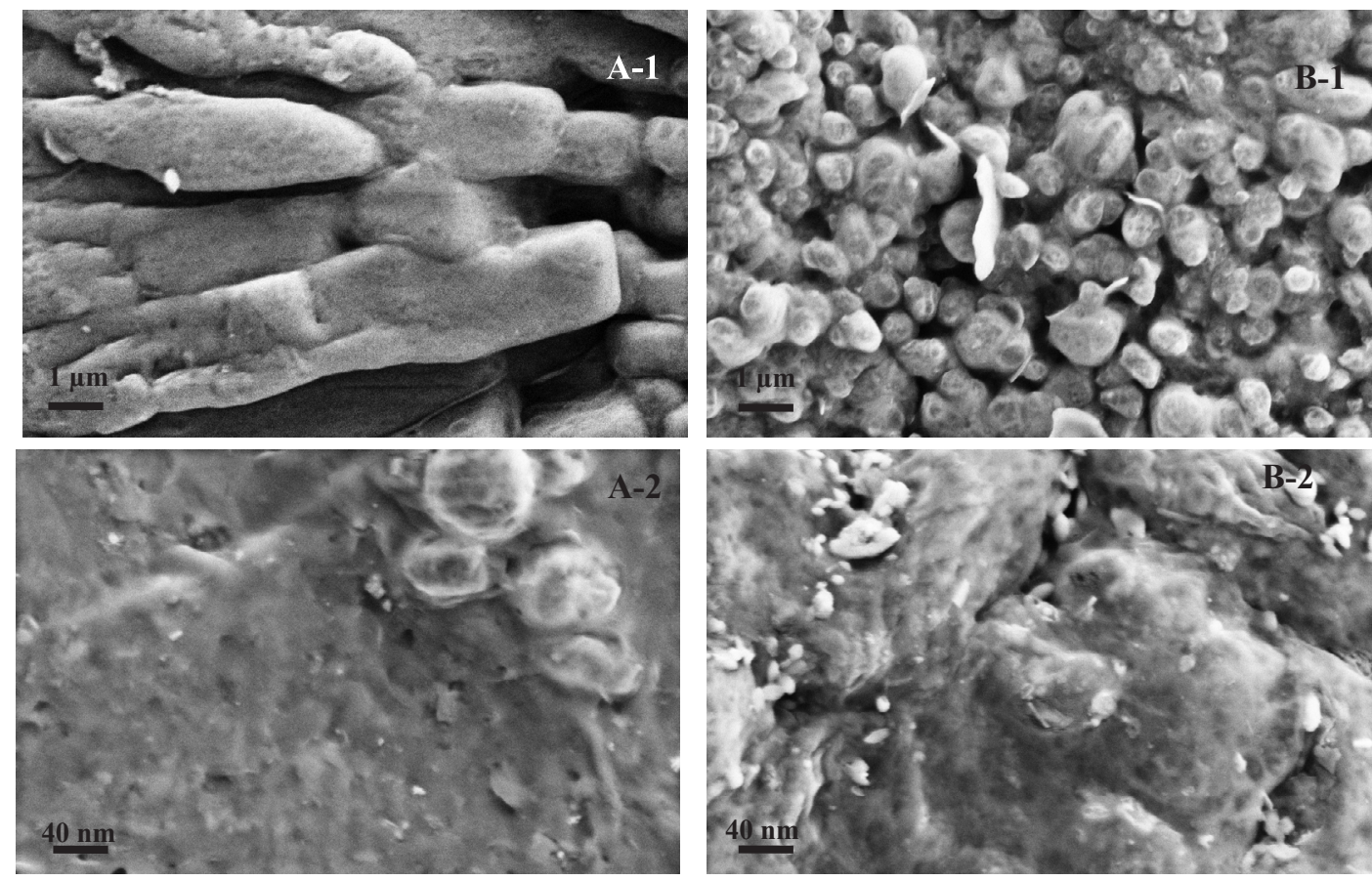

Fig. 1. Scanning electron microscopy micrographs of gelatin gel (A) and gelatin gel enriched with its hydrolysate (B). Magnifications: A1 and B1 (1000 × ), A2 and B2 $(3000 \times)$.

then performed and followed by Duncun test to estimate the significance among the main effects at the $5 \%$ probability level.

\section{Results and discussion}

\subsection{Gelatin gel characterization}

\subsubsection{Scanning electron microscopy analysis}

The structure of gelatin-based gel enriched or not with its hydrolysate, was evaluated by scanning electron microscopy analysis (Fig. 1). The microstructure of BG gel showed a typical morphology of gelatin gel materials (Fig. 1A). Gelatin-based gel contained a dense network of short and thick fibers organized in sheets, along with heterogeneous voids. Additionally, the morphology of BG gel showed a low porosity microstructure with visibly very small pores, similar to previous gelatins extracted from other sources such as cuttlefish skin gelatin (Jridi et al., 2015), commercial acid-soluble collagen skin (Potorac, Popa, Maier, Lisa, \& Verestiuc, 2012) and horse mackerel bones (Jansson, Haegerstrand, \& Kratz, 2001). Wang et al. (2014), reported in their study, that the collagen gel extracted from Amur sturgeon skin, showed an irregular dense fibrillar microstructure with high interconnection network and massive and porous nature. Generally, such hydrogel structure is useful for a large variety of applications, especially for food coating, or as a support material for bioactive substances. In fact, gelatin gel with small pore sizes leads to absorb a large amount of water and serve as texturing, gelling, stabilizing and emulsifying agent. On the other hand, Fig. 1 (B1 and B2) showed that the addition of peptides into the gelatin gel network had influence on the microstructure of BG gel leading to decrease the porosity, by occupying the empty pores observed in the initial structure. These results suggested that the secondary structure of gelatins was affected by the addition of peptides.

\subsubsection{Rheological properties}

Viscoelastic properties refer to the changes of viscoelastic modulus in sol-hydro gel conversion. Gelling properties of gelatin solutions $(6.67 \%, w / v)$ were measured through the programs of cooling and heating. The temperature at which the curves of $\mathrm{G}^{\prime}$ and $\mathrm{G}^{\prime \prime}$ joined is considered as the gelling point and is close to the sol-gel transition temperature. From the graph (Fig. 2), the gelling and melting temperatures of control gelatin were about $19.5^{\circ} \mathrm{C}$ and $25^{\circ} \mathrm{C}$, respectively. The observed behavior against the temperature is typical to previously studied fish skin gelatin extracted from Catla catla (Chandra \& Shamasundar, 2015). Similar to our findings, the cod skin gelatin showed gelling/melting temperatures of 21.2 and $27.4^{\circ} \mathrm{C}$, respectively (Cai et al., 2018). However, after peptides addition, these values significantly changed and the resulting bioactive gelling solution acquired new gelling and melting points of 20.5 and $21.9^{\circ} \mathrm{C}$, respectively. The slight decrease observed in the gelling temperature of fish gelatin added with BGH may be due to the fact that hydrolysate addition increased the penetration pores and thus the gelatin gel would be weaker. Similar observation was obtained by Surowka (1997), who demonstrated that, even in the range of the lowest hydrolysate concentrations, peptides addition affected negatively the gelatin network maintaining.

\subsection{Gelatin coated smooth hound fillets}

\subsubsection{Moisture loss}

The weight loss of fish samples was evaluated by measuring the weight of samples, coated or not, during the storage period at $4{ }^{\circ} \mathrm{C}$ (Fig. 3A). The results indicated that the weight loss was rapid in control samples (uncoated), whereas it slowed down in coated fillets. In fact, in the control group, the weight loss was estimated as $27 \%, 47 \%$ and $68 \%$ after 3, 6 and 8 days of storage, respectively. This abusive increase may be due to the absence of further external packaging (overwrap) to accentuate oxidation process in simulated fresh conditions. However, gelatin coating contributed to the decrease of moisture loss, which was significantly reduced to $46 \%, 44 \%$, and $47 \%$ in CG, BG and BG + BGH groups, respectively, after 8 days of storage. There were no significant differences in preventing weight loss between the fish samples coated in the different treated groups $(p>0.05)$. Previous studies showed that gelatin coatings act as barrier to water and reduce exudates that result in water loss in fresh fish fillet. In fact, Herring, Jonnalongadda, Narayanan, and Coleman (2010) reported moisture loss values ranged from $30 \%$ to $60 \%$ for coated and uncoated meat samples, respectively, 

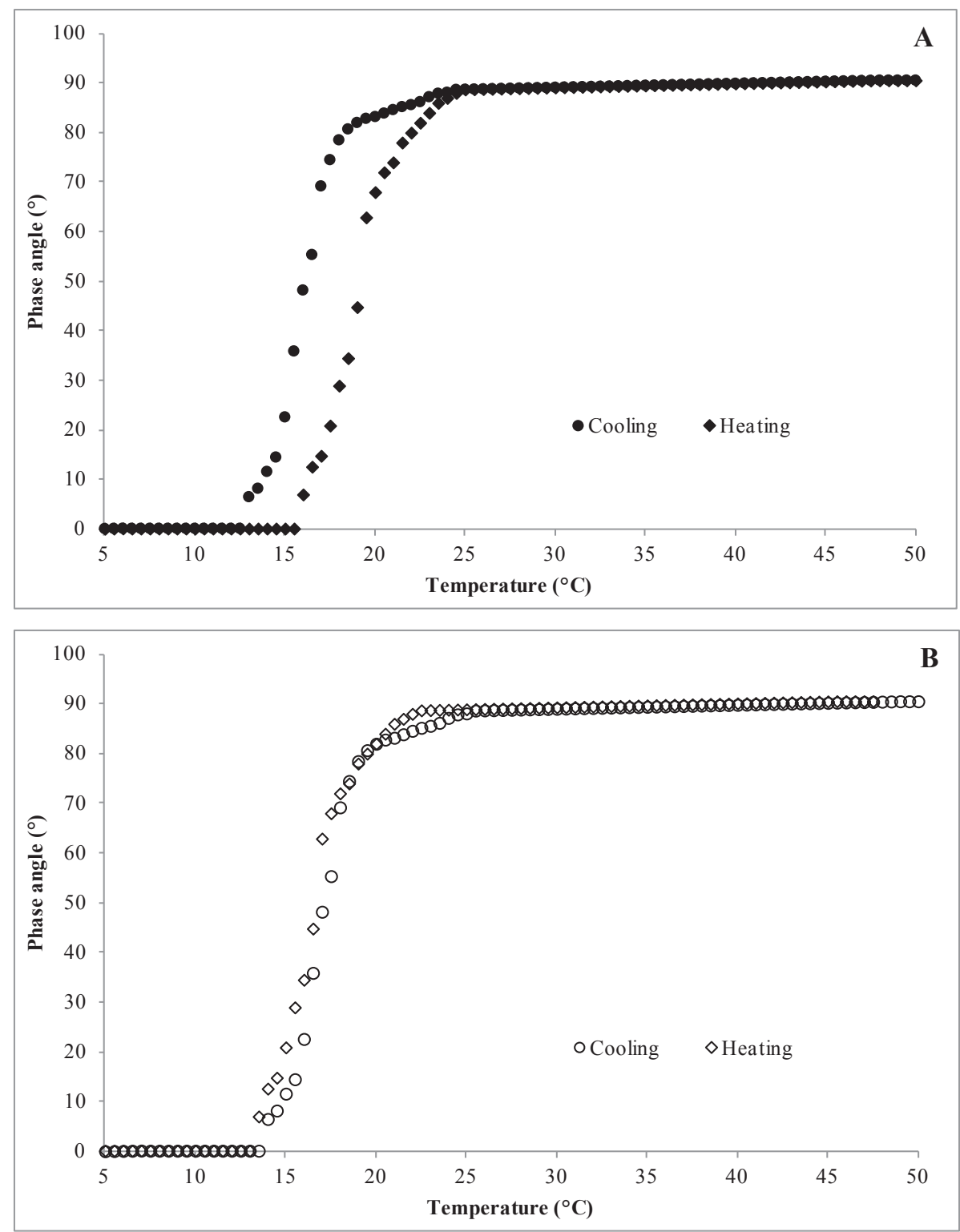

Fig. 2. Evolution of the phase angle during cooling from $50^{\circ} \mathrm{C}$ to $5{ }^{\circ} \mathrm{C}$ and heating from $5{ }^{\circ} \mathrm{C}$ to $50^{\circ} \mathrm{C}$ of black-barred skin gelatin gel alone (A) and enriched with its hydrolysate (B).

throughout the 7 days of storage period. In addition, Feng et al. (2016) reported the efficacy of gelatin coating in reducing moisture loss and proved that gelatin can reduce the purge of fish fillet during 17 days of chilled storage. Also, Farajzadeh, Motamedzadegan, Shahidi, and Hamzeh (2016) reported that chitosan-gelatin coating act as a barrier to water and reduce exudates resulting in the water loss of coated shrimps.

It is well known that gelatin is rich in hydrophobic amino acids, such as proline and leucine, capable to retain water, resulting in the prevention from moisture loss outside the fish fillet. Furthermore, the water holding capacity and water barrier properties of gelatin could explain the reduction of the weight loss in gelatin-coated samples (Limpisophon, Tanaka, Weng, Abe \& Osako, 2009).

\subsubsection{Changes in $\mathrm{pH}$, water activity and color parameters}

The effects of gelatin coating on changes in water activity $\left(\mathrm{a}_{\mathrm{w}}\right), \mathrm{pH}$ and color parameters of fish fillet during storage are shown in Table 1. Initially, the $\mathrm{pH}$ of all samples was close to neutral and then increased over time. In control samples, the $\mathrm{pH}$ increased to 8.72 after 6 days and then decreased to 7.35 at the end of the experimental period ( $8^{\text {th }}$ day). However, in coated fish samples, the $\mathrm{pH}$ continued to increase to reach
8.34 and 8.31 in CG and BG groups, respectively, which still significantly lower than the control group ( $\mathrm{p} \leq 0.05)$. Data showed no significant differences during the 8-days of storage in all the treated samples. The decrease in $\mathrm{pH}$ value after 8 days may be due to the production of lactic acid and dissolution of carbon dioxide into the fish aqueous phase (Lorenzo et al., 2014). Interestingly, high pH values recorded during the first period of storage may be due to the fish spoilage state and the production of free amino acids leading to the formation of $\mathrm{NH}_{3}$ groups caused by microorganisms' hydrolytic effect (Kakaei \& Shahbazi, 2016). However, the pH variation of coated fish fillets was slower than that of the control group, proving the beneficial effect of gelatin coating in maintaining the quality of fish during chilled storage. Lower $\mathrm{pH}$ value observed in coated fish samples is associated to the weight loss decrease in fresh fish, as previously reported by Alemán et al. (2016), when evaluating the effect of chitosan-gelatin-shrimp concentrate, as coating or film packaging, on the quality of fish sausages during chilled storage during 42 days.

Moreover, water activity $\left(\mathrm{a}_{\mathrm{w}}\right)$ is an important parameter in controlling microorganisms' growth of stored meats, and it may be defined as the amount of free water, available for bacterial growth, present in a 


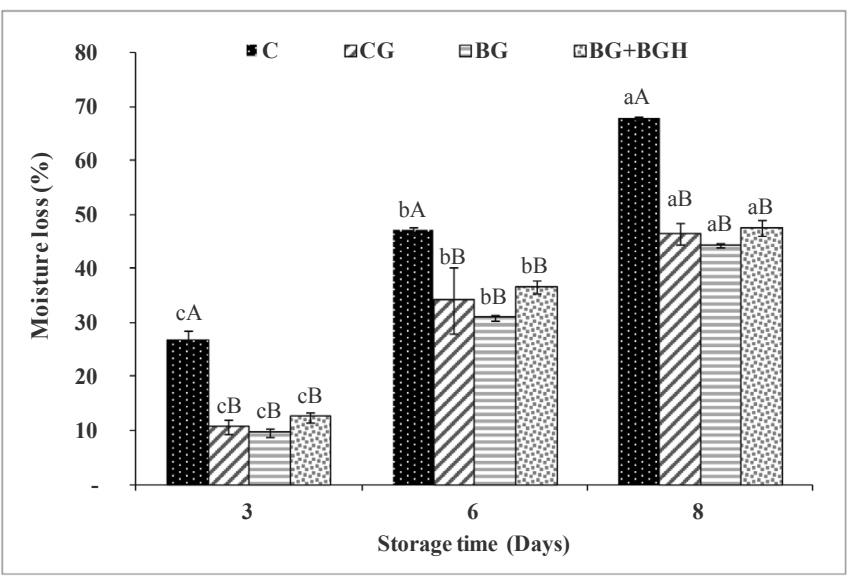

Fig. 3. Weight loss of the different fish samples measured at 0, 3, 6 and 8 days of storage. $\mathrm{C}$ represents the uncoated control group; CG and BG indicate commercial gelatin and Black-barred halfbeak gelatin, respectively; BG + BGH represent black barred halfbeak gelatin gel enriched with its hydrolysate. A,B: means in each treatment with different letters are significantly different $(P \leq 0.05)$; a,b,c: means in different days of storage with different letters are significantly different $(\mathrm{P} \leq 0.05)$.

product. Water activity is an important criterion for the evaluation and control of food safety and quality of foodstuffs, since the 1950s when it became obvious that water content is strongly related to the microbial growth limitations. Results of $\mathrm{a}_{\mathrm{w}}$ among all samples did not reveal any significant difference during the first 6 days of chilled storage. Contrary to uncoated group, in which $\mathrm{a}_{\mathrm{w}}$ values decreased to 0.83 on the $8^{\text {th }}$ day, treated fillets showed a constant $\mathrm{a}_{\mathrm{w}}$ evolution, that remains over 0.97 , indicating that coated meat conserve its initial freshness even after 8 days of storage. The obtained results are similar to those reported by Jridi et al. (2018). The steady $a_{w}$ values observed in coated groups may be due to the water vapor barrier property of gelatin material (Limpisophon, Tanaka, Weng, Abe \& Osako, 2009).

On the other hand, color is a crucial parameter in food quality control that influences consumers' demand. Table 1 illustrates color parameters changes of different fish samples coated or not with gelatin. During 8 days of chilled storage, results of uncoated samples clearly indicated that lightness values $\left(\mathrm{L}^{*}\right)$ significantly decreased, while they remained invariable in all the coated groups. In addition, based on visual observation, color of uncoated sample changed from yellow, dark yellow to brown, at the end of the experimental period. The observed brown color of fish muscle is essentially caused by oxygen, responsible to the oxidation of myoglobin to form metamyoglobin, which imparts a brownish color (Bekhit \& Faustman, 2005). However, colors of coated fish samples were slightly affected and the fish fillet still visually acceptable. In fact, according to Table 1 , the redness (a*) of uncoated fish increased with increasing storage time, and values were higher than those of treated one. Similarly, after 3, 6 and 8 days of storage, yellowness $\left(b^{*}\right)$ values of uncoated fish were dramatically decreased and they were estimated at 4.00, 2.89 and 0.26 , respectively. However, in CG and BG groups, b* values were moderately decreased to reach 2.83 and 2.51, respectively, in the last day. Particularly, BG and BGH coating was more effective than BG on preserving the color of the stored fish, where the best results were recorded for the BGH group when compared to the gelatin coated fish samples, showing the lowest $\mathrm{a}^{*}, \mathrm{~b}$ * and $C^{*}$ values (20.04, 4.45, and 20.53, respectively).

The obtained results are in agreement with previous studies dealing with turbot (Psetta maxima) fillets packaging (Santos et al., 2013) and Alaska Pollock surimi (Sell, Beamer, Jaczynski \& Matak, 2015). The

Table 1

Changes in $\mathrm{pH}, \mathrm{a}_{\mathrm{w}}$ and color parameters of fish samples at $0,3,6$ and 8 days of storage.

\begin{tabular}{|c|c|c|c|c|c|c|}
\hline \multirow[t]{2}{*}{ Attribute } & & \multirow[t]{2}{*}{ Treatments } & \multicolumn{4}{|c|}{ Storage time (Days) } \\
\hline & & & 0 & 3 & 6 & 8 \\
\hline \multirow[t]{4}{*}{$\mathrm{pH}$} & & Control & $6.69 \pm 0.02^{\mathrm{Da}}$ & $8.30 \pm 0.02^{\mathrm{Ba}}$ & $8.72 \pm 0.04^{\mathrm{Aa}}$ & $7.35 \pm 0.02^{\mathrm{Cb}}$ \\
\hline & & & $6.68 \pm 0.04^{\mathrm{Da}}$ & $7.25 \pm 0.00^{\mathrm{Cb}}$ & $8.03 \pm 0.05^{\mathrm{Bb}}$ & $8.34 \pm 0.01^{\mathrm{Aa}}$ \\
\hline & & & $6.65 \pm 0.03^{\mathrm{Aa}}$ & $7.10 \pm 0.02^{\mathrm{Ac}}$ & $8.00 \pm 0.04^{\mathrm{Ab}}$ & $8.31 \pm 0.02^{\mathrm{Aa}}$ \\
\hline & & $\mathrm{BG}+\mathrm{BGH}$ & $6.70 \pm 0.01^{\mathrm{Da}}$ & $7.13 \pm 0.02^{\mathrm{Cd}}$ & $8.00 \pm 0.04^{\mathrm{Bb}}$ & $8.31 \pm 0.02^{\mathrm{Aa}}$ \\
\hline \multirow[t]{4}{*}{$\mathrm{a}_{\mathrm{w}}$} & & Control & $0.99 \pm 0.00^{\mathrm{Aa}}$ & $0.98 \pm 0.01^{\mathrm{Aa}}$ & $0.90 \pm 0.01^{\mathrm{Ba}}$ & $0.83 \pm 0.00^{\mathrm{Cb}}$ \\
\hline & & & $0.99 \pm 0.00^{\mathrm{Aa}}$ & $0.98 \pm 0.01^{\mathrm{Aa}}$ & $0.99 \pm 0.00^{\mathrm{Aa}}$ & $0.99 \pm 0.05^{\mathrm{Aa}}$ \\
\hline & & & $0.98 \pm 0.00^{\mathrm{Ab}}$ & $0.99 \pm 0.01$ Аa & $0.98 \pm 0.01^{\mathrm{Aa}}$ & $0.97 \pm 0.01 \mathrm{Aa}$ \\
\hline & & $\mathrm{BG}+\mathrm{BGH}$ & $0.99 \pm 0.00^{\mathrm{Aa}}$ & $0.99 \pm 0.00^{\mathrm{Aa}}$ & $0.98 \pm 0.00^{\mathrm{Aa}}$ & $0.97 \pm 0.02^{\mathrm{Aa}}$ \\
\hline \multirow[t]{16}{*}{ Color parameters } & $L^{*}$ & Control & $27.32 \pm 1.02^{\mathrm{Ba}}$ & $29.00 \pm 0.00^{\mathrm{Aa}}$ & $21.04 \pm 0.36^{\mathrm{Cb}}$ & $12.01 \pm 0.95^{\mathrm{Db}}$ \\
\hline & & & $28.42 \pm 0.96^{\mathrm{Aa}}$ & $29.20 \pm 0.13^{\mathrm{Aa}}$ & $28.91 \pm 1.00^{\mathrm{Aa}}$ & $27.35 \pm 1.46^{\mathrm{Aa}}$ \\
\hline & & & $27.95 \pm 0.46^{\mathrm{Aa}}$ & $29.25 \pm 1.43^{\mathrm{Aa}}$ & $28.36 \pm 1.30^{\mathrm{Aa}}$ & $26.05 \pm 1.96$ Aa \\
\hline & & $\mathrm{BG}+\mathrm{BGH}$ & $27.30 \pm 0.75^{\mathrm{Aa}}$ & $27.48 \pm 0.94^{\mathrm{Ab}}$ & $28.00 \pm 1.31 \mathrm{Aa}$ & $27.61 \pm 1.01 \mathrm{Aa}$ \\
\hline & $a^{*}$ & Control & $20.05 \pm 1.40^{\mathrm{Da}}$ & $32.96 \pm 0.96^{\mathrm{Ca}}$ & $35.48 \pm 0.72^{\mathrm{Ba}}$ & $49.36 \pm 0.09 \mathrm{Aa}$ \\
\hline & & & $21.03 \pm 1.00^{\mathrm{Ba}}$ & $23.97 \pm 2.24^{\mathrm{Bc}}$ & $25.74 \pm 3.34^{\mathrm{Bb}}$ & $35.50 \pm 1.68^{\mathrm{Ab}}$ \\
\hline & & & $21.23 \pm 1.29 \mathrm{Ca}$ & $27.69 \pm 0.16^{\mathrm{Bb}}$ & $34.89 \pm 1.27^{\mathrm{Aa}}$ & $32.75 \pm 0.75^{\mathrm{Ab}}$ \\
\hline & & $\mathrm{BG}+\mathrm{BGH}$ & $20.95 \pm 0.59^{\mathrm{Aa}}$ & $20.65 \pm 0.16^{\mathrm{Ad}}$ & $21.65 \pm 1.27^{\mathrm{Ac}}$ & $20.04 \pm 0.70^{\mathrm{Ac}}$ \\
\hline & $b^{*}$ & Control & $4.24 \pm 0.40^{\mathrm{Aa}}$ & $4.00 \pm 0.10^{\mathrm{Aa}}$ & $2.89 \pm 0.10^{\mathrm{Bb}}$ & $0.26 \pm 0.03^{\mathrm{Cc}}$ \\
\hline & & CG & $4.36 \pm 0.30^{\mathrm{Aa}}$ & $4.17 \pm 0.00^{\mathrm{Aa}}$ & $4.55 \pm 0.25^{\mathrm{Aa}}$ & $2.83 \pm 0.03^{\mathrm{Bb}}$ \\
\hline & & BG & $4.26 \pm 0.24^{\mathrm{Aa}}$ & $4.08 \pm 0.25^{\mathrm{Aa}}$ & $4.47 \pm 1.1^{\mathrm{Aa}}$ & $2.51 \pm 0.67^{\mathrm{Bb}}$ \\
\hline & & $\mathrm{BG}+\mathrm{BGH}$ & $4.33 \pm 0.14^{\mathrm{Aa}}$ & $4.08 \pm 0.45^{\mathrm{Aa}}$ & $4.77 \pm 1.1^{\mathrm{Aa}}$ & $4.45 \pm 0.09^{\mathrm{Aa}}$ \\
\hline & $\mathrm{C}^{*}$ & Control & $20.49 \pm 0.59^{\mathrm{Da}}$ & $32.91 \pm 1.24^{\mathrm{Ca}}$ & $35.60 \pm 0.02^{\mathrm{Ba}}$ & $49.36 \pm 2.68^{\mathrm{Aa}}$ \\
\hline & & CG & $21.48 \pm 1.26^{\mathrm{Ca}}$ & $24.33 \pm 0.68^{\mathrm{Bc}}$ & $26.18 \pm 0.63^{\mathrm{Bb}}$ & $35.61 \pm 0.23^{\mathrm{Ab}}$ \\
\hline & & BG & $21.65 \pm 0.75^{\mathrm{Ca}}$ & $27.99 \pm 0.15^{\mathrm{Bb}}$ & $25.18 \pm 0.63^{\mathrm{Bb}}$ & $32.85 \pm 0.65^{\mathrm{Ab}}$ \\
\hline & & $\mathrm{BG}+\mathrm{BGH}$ & $21.39 \pm 0.57^{\mathrm{Ba}}$ & $21.05 \pm 0.02^{\mathrm{Bd}}$ & $22.17 \pm 0.22^{\mathrm{Ac}}$ & $20.53 \pm 0.79^{\mathrm{Cc}}$ \\
\hline
\end{tabular}

A,B,C,D: For each attribute, means in the same line with different letters are significantly different $(\mathrm{P}<0.05)$; a,b,c,d: For each attribute, means within a column, with different letters are significantly different $(\mathrm{P}<0.05)$.

CG and BG indicate bovine commercial gelatin and black-barred halfbeak gelatin, respectively; BG + BGH represent black-barred halfbeak gelatin gel enriched with the gelatin hydrolysate. 

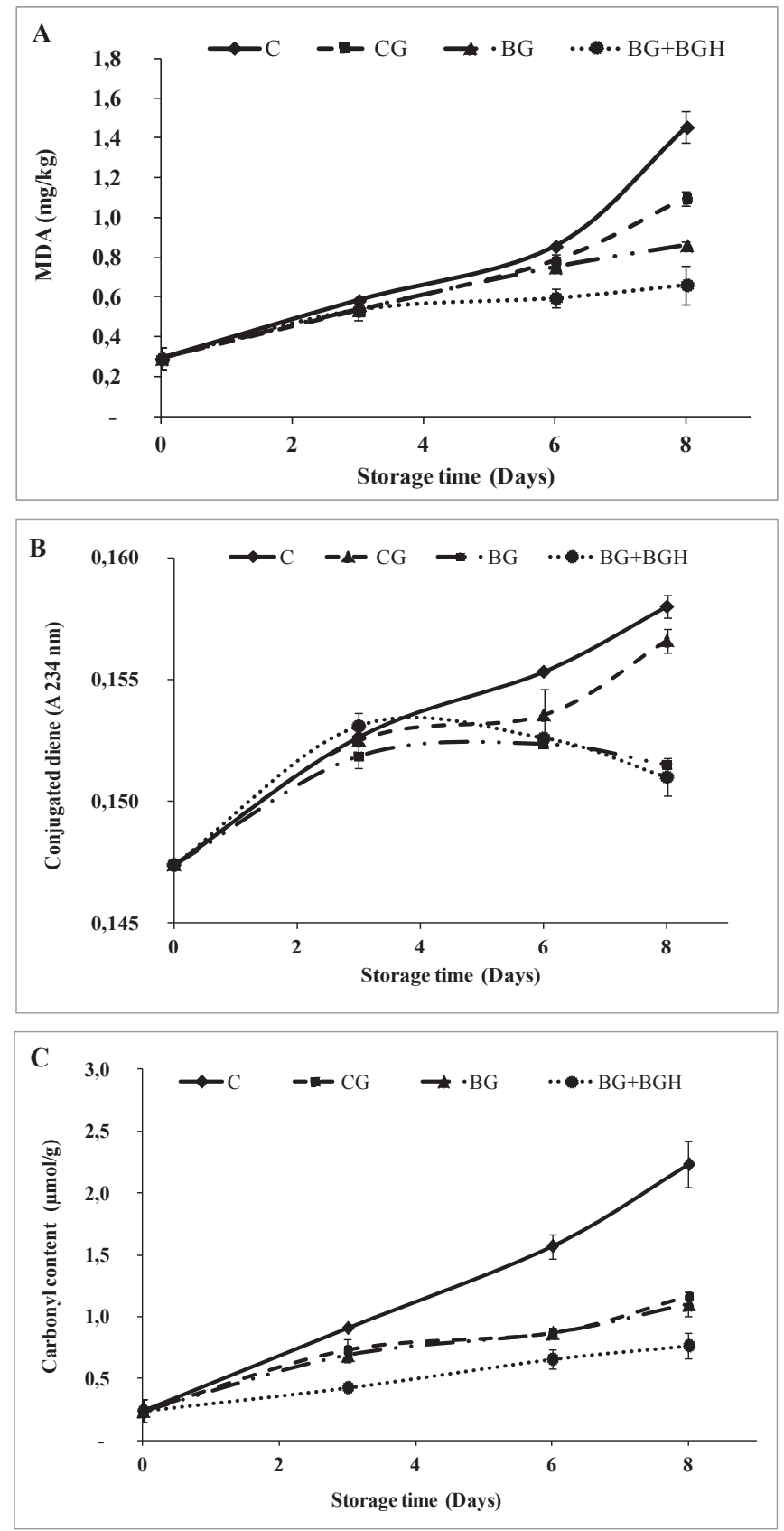

Fig. 4. Lipid oxidation (mg MDA/kg of fish fillet) (A), conjugated diene $\left(\mathrm{A}_{234 \mathrm{~nm}}\right)(\mathrm{B})$ and carbonyl content $(\mu \mathrm{mol} / \mathrm{g}$ ) (C) of fish samples measured at 0 , 3,6 and 8 days of storage.

application of a gelatin coating did not affect the initial color parameters of fish fillet, which encourage its use for food products packaging without affecting consumers' desires. In fact, the coating formed a very fine layer that could drain away after application, giving less coloring to the fillets. In addition, gelatin coating offer an excellent barrier to avoid oxygen penetration involving in preserving fish fillet against myoglobin oxidation and therefore color loss. In their study, Feng et al. (2016) demonstrated that the use of gelatin as edible coating form a barrier against oxygen and protect golden pomfret fillet during cold storage. In this study, the protective effect of gelatin was considerably improved by the addition of $\mathrm{BGH}$, previously showing great antioxidant activity (Abdelhedi et al., 2017).

\subsubsection{Lipid oxidation}

Lipid oxidation is a main factor limiting the shelf-life of marine products. Lipid peroxidation during fish storage was measured in terms of thiobarbituric reactive substances (TBARS) ( $\mathrm{mg}$ of malondialdehyde (MDA) per $\mathrm{kg}$ of fish sample) and conjugated dienes (Fig. 4A and B). Results showed that MDA and specific extinctions coefficients of different samples increased during storage period. Up to the $3^{\text {rd }}$ day of chilled storage, there was no significant difference in MDA content and conjugated dienes between uncoated and gelatin-coated samples. Nevertheless, the control group showed the highest MDA content (1.46 of MDA $/ \mathrm{kg}$ of fish) after 8 days of storage, while BG + BGH coated fillets exhibited the lowest MDA content $(0.66 \mathrm{mg}$ of MDA $/ \mathrm{kg})$, among all studied samples $(p \leq 0.05)$. In fact, the MDA content has been reduced by $25 \%, 41 \%$ and $54 \%$, respectively, after CG, BG and BG + BGH coatings (Fig. 4A). Similarly, for the conjugated diene level, BG + BGHcoated samples displayed the lowest values all over the storage period (Fig. 4B). Gelatin hydrolysates are known by their antioxidant potential involved in the inhibition of the early stages of lipid oxidation as well as the delay of the oxidation process propagation (Jridi et al., 2014). These results suggest that gelatin hydrolysate contains bioactive peptides, which could react with free radicals to convert them to more stable products and terminate the radical chain reaction, resulting in the protection from lipid peroxidation. In this context, Jridi et al. (2014) demonstrated that gelatin hydrolysis generated peptides, with electron donating potential, to terminate lipid peroxidation reaction.

In this context, Nowzari, Shábanpour and Ojagh (2013) demonstrated that gelatin-chitosan coating reduced TBARS level in refrigerated rainbow trout fillets during 16 days of storage. Similarly, Nikoo, Benjakul and Xu (2015) showed that Amur sturgeon skin gelatin hydrolysates were effective in preventing lipid oxidation as evidenced by the lower MDA formation in unwashed fish mince. Farajzadeh et al. (2016) reported also that both antioxidant and oxygen barrier properties of gelatin contributed to control the lipid oxidation of shrimp under refrigerated condition. Chicken breast fillets, likewise, wrapped in starch-gelatin exhibited very slow lipid oxidation throughout storage (Moreno, Atarés, Chiralt, Cruz-Romero, \& Kerry, 2018).

A gelatin coat on fresh meat products should reduce lipid oxidation because the hydrogen bonds present in gelatin act as a barrier to oxygen (Antoniewski, Barringer, Knipe, \& Zerby, 2007). On the other hand, Marggrander and Hofmann (1997) studied the lipid oxidation of gelatin coated fish and found lower level of MDA compared to uncoated sample. These authors attributed the protective effect of gelatin films to the presence of ionic functional groups, which create strong polymerfish interaction, resulting in good oxygen barrier properties. Thus, it could be concluded that gelatin is a good barrier to oxygen diffusion and its potential could be strongly enhanced by the addition of bioactive molecules, such as gelatin hydrolysates.

\subsubsection{Protein oxidation}

Protein oxidation of the fish samples was analyzed by the quantification of carbonyl compounds ( $\mu \mathrm{mol})$ per $g$ of protein extracted. As shown in Fig. 4C, carbonyl level increased for all the groups as the storage time progressed through 8 days of storage, indicating that the proteins would be more oxidized with the progression of time. A significant difference $(p \leq 0.05)$ was recorded between carbonyl content in control and coated fish fillets. However, no significant difference $(p>0.05)$ was observed between the two gelatin (bovine and that from black-barred halfbeak skin) coating treatments on the carbonyl compounds level during all the days of storage. Nevertheless, BG + BGH-coated group showed the lowest oxidized proteins level estimated at $0.43,0.66$ and $0.77 \mu \mathrm{mol} / \mathrm{g}$ of protein on day 3,6 and 8 , respectively. This result leads to suggest that the amount of antioxidants (gelatin hydrolysate) in fish was enough to prevent from fish 
Table 2

Free amino acid and nucleotide contents of fish samples measured at 0, 3, 6 and 8 days of storage.

\begin{tabular}{|c|c|c|c|c|c|c|c|c|c|c|c|c|c|c|}
\hline & & \multirow[t]{2}{*}{ Day 0} & \multicolumn{3}{|c|}{ Control « un-coated» } & \multicolumn{3}{|l|}{ CG } & \multicolumn{3}{|l|}{ BG } & \multicolumn{3}{|c|}{$\mathrm{BG}+\mathrm{BGH}$} \\
\hline & & & Day 3 & Day 6 & Day 8 & Day 3 & Day 6 & Day 8 & Day 3 & Day 6 & Day 8 & Day 3 & Day 6 & Day 8 \\
\hline \multirow{17}{*}{$\begin{array}{l}\text { Free amino acids } \\
\qquad(\mu \mathrm{g} / \mathrm{g} \text { of sample) }\end{array}$} & Asp & 91.75 & 75.73 & 71.26 & 178.32 & 80.26 & 80.98 & 80.36 & 86.85 & 96.65 & 75.15 & 90.32 & 90,25 & 90.33 \\
\hline & Glu & 115.04 & 273.91 & 288.13 & 337.92 & 115.20 & 200.00 & 200.63 & 201.76 & 177.35 & 188.97 & 103.65 & 179,36 & 180.39 \\
\hline & Ser & 42.68 & 108.68 & 105.33 & 171.64 & 31.02 & 100.20 & 103.25 & 66.56 & 150.00 & 160.13 & 46.03 & 50,3 & 50.16 \\
\hline & Gly & 242.96 & 262.36 & 301.42 & 682.36 & 258.36 & 248.63 & 335.65 & 276.35 & 337.56 & 412.60 & 225.36 & 260,5 & 262.85 \\
\hline & His & 241.36 & - & - & - & 221.38 & 32.44 & - & 242.63 & 33.47 & 30.32 & 251.36 & 159,7 & 149.50 \\
\hline & Thr & 73.50 & 73.27 & 61.48 & 103.16 & 62.16 & 64.74 & 65.60 & 79.20 & 79.20 & 68.26 & 73.25 & 76,3 & 79.36 \\
\hline & Ala & 63.97 & - & - & - & 48.93 & 46.53 & 43.67 & 64.64 & 51.87 & 52.68 & 63.90 & 55,5 & 55.89 \\
\hline & Arg & 42.27 & - & - & - & 49.36 & 43.78 & 38.11 & 64.22 & 38.63 & 31.00 & 46.72 & 45,34 & 44.33 \\
\hline & Pro & 128.32 & 100.30 & 101.50 & 90.83 & 113.22 & 101.50 & 99.47 & 105.60 & 105.62 & 109.60 & 105.32 & 100,78 & 98.36 \\
\hline & Tyr & 225.67 & 456.35 & 1421.25 & 1475.00 & 222.20 & 215.36 & 527.84 & 375.46 & 354.00 & 335.60 & 387.20 & 458 & 457.80 \\
\hline & Val & 1308.20 & 1528.40 & 1206.80 & 2960.6 & 1363.25 & 1614.16 & 1754.83 & 1466.93 & 1429.35 & 1426.80 & 1400.00 & 1270,3 & 1249.2 \\
\hline & Ile & 24.70 & 45.12 & 41.39 & 178.60 & 22.02 & 44.99 & 44.44 & 25.96 & 38.73 & 40.53 & 30.21 & 35,79 & 34.34 \\
\hline & Leu & 141.74 & 191.17 & 163.23 & 270.25 & 148.20 & 150.63 & 149.21 & 140.02 & 145.68 & 149.65 & 155.25 & 156,1 & 160.01 \\
\hline & Phe & - & - & - & 11.07 & 3.78 & - & - & 19.83 & - & 8.33 & 8.12 & 10,2 & 9.94 \\
\hline & $\operatorname{Trp}$ & 4.99 & 5.59 & 6.51 & 13.44 & 5.71 & 5.97 & 6.00 & 5.00 & 6.01 & 5.36 & 4.78 & 5,31 & 5.57 \\
\hline & Lys & 3.35 & 65.24 & 67.03 & 62.07 & 4.28 & 8.35 & 7.87 & 3.48 & 4.48 & 6.57 & 5.24 & 5,59 & 5.62 \\
\hline & Total (mg/g) & 2.75 & 3.19 & 6.84 & 6.54 & 2.75 & 2.96 & 3.46 & 3.22 & 3.04 & 3.10 & 3.00 & 2.95 & 2.93 \\
\hline \multirow[t]{7}{*}{ Nucleotide $(\mu$ moles/g) } & ATP & 199.21 & 106.64 & 0.02 & 0.03 & 199.79 & 81.34 & 73.37 & 188.82 & 87.47 & 76.77 & 180.72 & 123.73 & 76.62 \\
\hline & $\mathrm{ADP}$ & 48.50 & 20.79 & 17.47 & 0.27 & 17.69 & 17.87 & 14.90 & 26.92 & 15.11 & 15.04 & 21.15 & 21.96 & 19.45 \\
\hline & AMP & 265.68 & 268.60 & 59.73 & 14.58 & 200.68 & 207.19 & 195.30 & 210.39 & 179.20 & 157.90 & 259.30 & 253.30 & 260.32 \\
\hline & IMP & 1697.59 & 1176.69 & 899.03 & 667.93 & 980.34 & 967.17 & 691.29 & 1053.82 & 1760.20 & 904.00 & 1176.30 & 1547.9 & 1495.32 \\
\hline & $\mathrm{Hx}$ & 661.61 & 775.82 & 501.25 & 423.19 & 821.06 & 507.29 & 412.21 & 674.91 & 443.98 & 538.77 & 767.71 & 538.34 & 700.24 \\
\hline & Ino & 1402.72 & 1058.81 & 749.21 & 584.55 & 1033.79 & 780.04 & 607.14 & 1147.46 & 900.01 & 800.48 & 975.37 & 584.3 & 235.90 \\
\hline & Ud & 24.15 & 152.34 & 297.56 & 487.36 & 103.20 & 251.42 & 356.20 & 92.35 & 105.96 & 204.38 & 22.65 & 15.20 & 8.76 \\
\hline
\end{tabular}

Values are the mean of the different determinations.

meat proteins' oxidation during storage at $4{ }^{\circ} \mathrm{C}$. Herring et al. (2010) showed that the carbonyl compounds increased for all the samples as the days progressed through 7 days of storage, and values were significantly lower after gelatin coating treatment.

Proteins are attacked by reactive oxygen species generated by diverse external factors, such as manipulation, slaughter, or the presence of metals (iron). The interaction can lead to the formation of carbonyl groups, affecting structural, functional, and nutritional properties of fish muscle. Furthermore, protein oxidation induces the decrease of water holding capacity as the protein network would be more friable, once proteins were oxidized (Feng et al., 2016). Morachis-Valdez et al. (2017) demonstrated also that chitosan coating prevented common carp (Cyprinus carpio) fillet from protein oxidation, during its storage in the freezer.

\subsubsection{Free amino acids quantification}

The free amino acid (FAA) contents in all fish samples were determined and results are presented in Table 2. The total content of FAA in uncoated fish fillets was $2.75 \mu \mathrm{g} / \mathrm{g}$ and $6.84 \mu \mathrm{g} / \mathrm{g}$ of fish meat before and after 6 days of storage, respectively. By contrast, this rise was significantly lower in coated fish groups, and no significant increase was noted in fish samples coated with BG + BGH after 8 days of storage ( $2.93 \mu \mathrm{g} / \mathrm{g}$ of fillet). The increase in the FAA quantities is mainly due the hydrolysis of meat proteins by the microorganisms developed during storage. Nevertheless, during the last two days, total FAA decreased (from 6.84 to $6.54 \mu \mathrm{g} / \mathrm{g}$ ) in uncoated fillets, which may be explained by the consumption of available amino acids by endogenous bacteria during their growth. Particularly, His, Ala, and Arg were completely degraded since the first 3 days of storage at $4{ }^{\circ} \mathrm{C}$, while this degradation was delayed by 3 additional days after CG or BG coating.

It has been reported that the content of FAA in fish muscle depend on the activation of neutral amino-peptidases at high $\mathrm{pH}$ value (Kakaei \& Shahbazi, 2016). This decrease was, however, absent in coated smooth hound fillets, thanks to the barrier role played by the gelatin against bacteria proliferation. As the same, Jridi et al. (2018) showed that the uncoated control meat had the highest FAA content, while it was significantly reduced in gelatin coated ones after 8 days of storage.

\subsubsection{Nucleotides quantification}

Post-mortem degradation of ATP in fish muscle occurs due to the hydrolytic effect of endogenous enzymes. This degradation goes through the intermediate products ADP, AMP, inosine mono-phosphate (IMP), inosine (Ino), and hypoxanthine ( $\mathrm{Hx}$ ). Most of the adenosine nucleotides disappear quickly because they are degraded into IMP within the first days after fish capture, and as the degradation continues, Ino and then Hx will be produced (Souza et al., 2010). Thus, the high inosine and hypoxanthine levels indicated about the development of fish spoilage. In this study, the quantification of nucleotides in the different groups was carried out in order to evaluate fish freshness (Table 2).

Results showed that adenosine triphosphate (ATP), adenosine diphosphate (ADP) and adenosine monophosphate (AMP) levels decreased with time in all the groups, and their degradation rate was faster in control samples than in coated ones $(p \leq 0.05)$. On the other hand, the decrease of IMP was accompanied with a proportional increase of uridine (Ud). In coated samples, however, the nucleotides degradation was slower, where BG and BG + BGH treated samples showed the highest ATP, ADP and AMP contents and the lowest Ud contents after 8 days $(p \leq 0.05)$. Özogul, Taylor, Quantick, and Özogul (2000) reported that freshness indicators related to the nucleotides degradation are mainly based on the autolysis of ATP in the muscle. Additionally, the rapid rise of degradation is entirely due to the sharp decline of IMP in the fish flesh. The loss of IMP through degradation to $\mathrm{Hx}$ and Ino would cause the loss of fish freshness.

In this context, several works have studied the changes in the nucleotides metabolism and they found, similarly, increased levels in Ino and Hx during fish processing (Souza et al., 2010). In addition, Fan et al. (2009) showed that chitosan coating was effective in inhibiting the degradation of ATP and extending the frozen storage life of fish samples, showing a reduction of $45 \%$ of nucleotide degradation after 7 


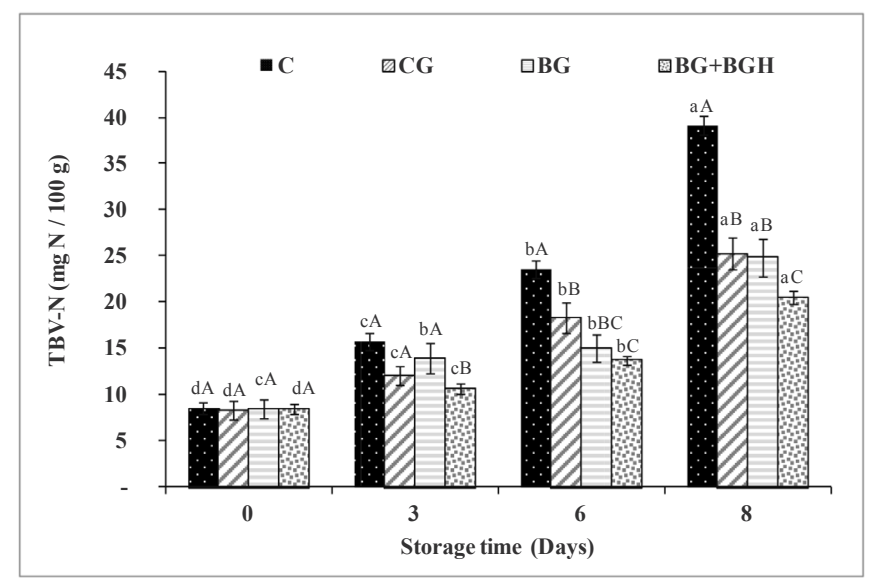

Fig. 5. Total volatile basic nitrogen (TVB-N) (mg N/100 g) at 0, 3, 6 and 8 days of storage. A,B,C: means in each treatment with different letters are significantly different $(\mathrm{P} \leq 0.05)$; a,b,c,d: means in different days of storage with different letters are significantly different $(\mathrm{P} \leq 0.05)$.

days of frozen storage. The oxygen barrier property of gelatin helps to prevent fillets against oxidation, implied in ATP degradation, resulting therefore in extending the shelf-life of fish fillets (Andevari \& Rezaei, 2011).

\subsubsection{Total volatile basic nitrogen}

As the fish spoilage progresses, total volatile basic nitrogen (TVB-N) compounds develop and their increasing levels are regularly used as an indicator of the spoilage of fish products (Santos et al., 2013). Fig. 5 shows the variation of TVB-N contents during the chilled storage of smooth hound fillet. The initial TVB-N was about $8.5 \mathrm{mg} \mathrm{N} / 100 \mathrm{~g}$ of sample in all the groups. Thereafter, this value increased gradually with the time of storage and it was evident that the most rapid rate of increase was found in the control group. In fact, after 6 days of storage, TVB-N value reached 23.57, 18.30, 15.0 and $13.73 \mathrm{mg} \mathrm{N} / 100 \mathrm{~g}$ in control, CG, BG and BG + BGH groups, respectively. The protective effect of gelatin coating was further recorded after 8 days of storage, and the BG + BGH treatment was able to reduce the TVB-N content to $20.49 \mathrm{mg} \mathrm{N} / 100 \mathrm{~g}$, whereas it was equal to $39.10 \mathrm{mg} \mathrm{N} / 100 \mathrm{~g}$ in the uncoated fillet. At the end of the storage, TVB-N value didn't reach the acceptable limit of 25-35 mg N/100 g of fish (EC Commission Regulation 1022/2008), except for control sample (39.10 mg N/100 g), which proves that coated fillets still preserve their freshness. Furthermore, there was no significant difference between CG and BG ( $p>0.05$ ), but a clear difference was recorded between BG and BG + BGH-coating $(p \leq 0.05)$. The increase in TVB-N content may be attributed to ammonia produced from bacterial catabolism of nitrogencontaining compounds (Arancibia, López-Caballero, Gómez-Guillén, \& Montero, 2015). The catabolism of amino acids in fish muscle results in the accumulation of different products such as, ammonia, monoethylamine, dimethylamine, trimethylamine, and other volatile bases, which affect sensory properties of fish (Huang et al., 2012).

Our results were similar to those of Ojagh, Rezaei, Razavi, and Hosseini (2010) who demonstrated that coated and uncoated rainbow trout fillets contained 22.86 and $42.93 \mathrm{mg} \mathrm{N} / 100 \mathrm{~g}$, respectively, after 8 days of refrigerated storage. Likewise, Andevari and Rezaei (2011) found that gelatin coating incorporated with cinnamon oil significantly lowered the TVB-N content of rainbow trout fish. In addition, Farajzadeh et al. (2016) reported that chitosan-gelatin coating of shrimp (Litopenaeus vannamei) caused a reduction of $35 \%$ in the formation TVB-N after 14 days of storage period.

It can be concluded that coating with gelatin/hydrolysate is more effective than the gelatin applied alone. These effects may be attributed to the inhibitory activity of microbial growth exerted by BGH. Overall,
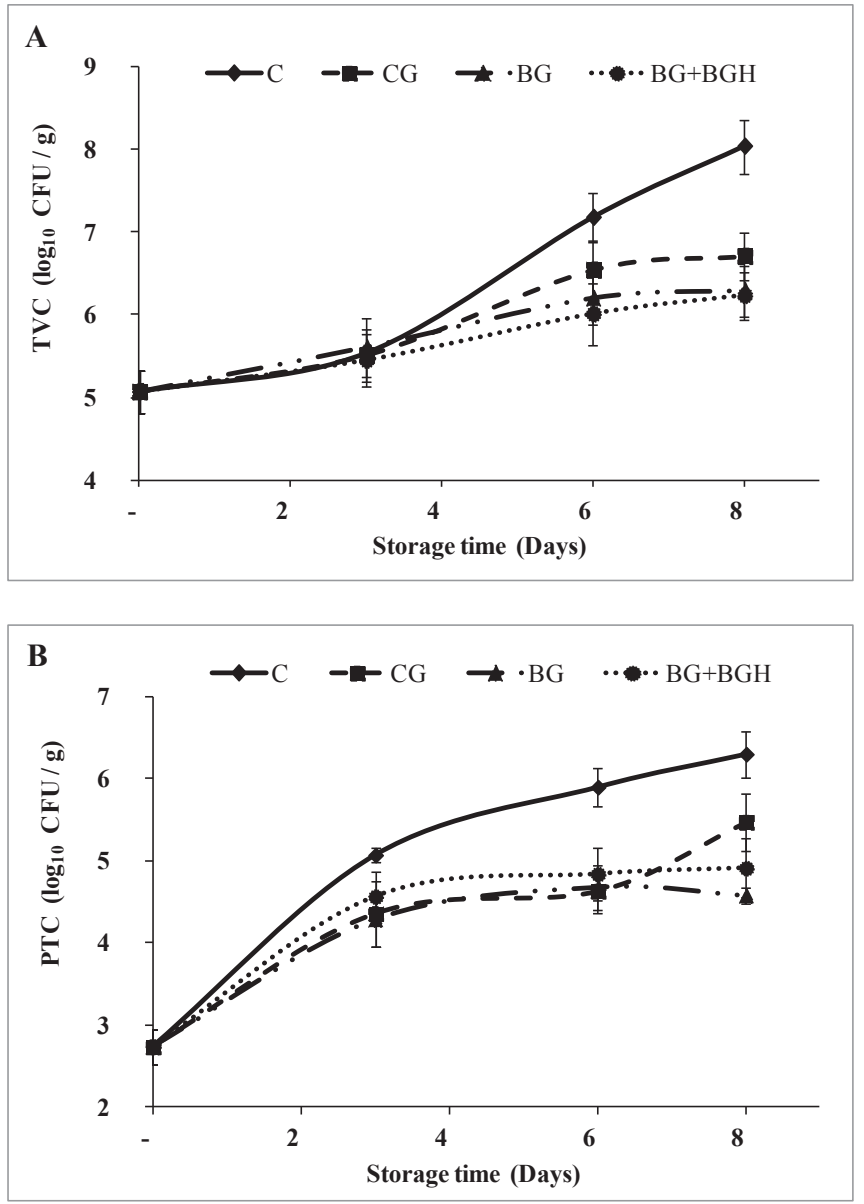

Fig. 6. Total viable counts (TVC) (A) and psychrotrophic counts (PTC) (B) of fish samples at $0,3,6$ and 8 days of storage.

the TVB-N results are in accordance with the lipid and protein oxidation as well as fish color. This study revealed, therefore, that gelatin coating helps to prevent color deterioration and meat oxidation of fish fillets and its effect may be improved by the addition of peptides as bioactive agent.

\subsubsection{Microbiological quality during storage}

The total viable count (TVC) of bacteria is a key indicator of the quality of fish fillets. Changes in microbial populations in fish fillets during storage were determined and the results are shown in Fig. 6. On the first day, the total viable (TVC) and psychrotrophic (PTC) counts were about 5 and $3 \log _{10} \mathrm{CFU} / \mathrm{g}$, respectively, thanks to hygienic conditions used during transport, slaughter and manipulation of fish fillets. During storage time, these levels trend to be markedly increased in all samples and reached, at the last day, $8 \log _{10} \mathrm{CFU} / \mathrm{g}$ (TVC) and 6.3 $\log _{10}$ CFU/g (PTC) in control fillets. Nonetheless, as compared to control samples, gelatin coating significantly reduced TVC and PTC $(p<0.05)$, delayed and restricted the growth of microorganisms. Particularly, BG + BGH lead to $1.77 \log _{10} \mathrm{CFU} / \mathrm{g}$ reduction in TVC and $1.45 \log _{10}$ CFU/g in PTC, after 8 days of storage. Further, there was no significant difference between $\mathrm{BG}$ and $\mathrm{BG}+\mathrm{BGH}$ treatments ( $\mathrm{p}>$ 0.05). According to the International Commission on Microbiological Specifications for Foods (ICMSF, 1986), the limit established for a bacterial count in fish is $7 \log \mathrm{CFU} / \mathrm{g}$. This limit can be applied for both TVC and PTC. Thus, the gelatin-coating could be an effective way to extend the storage time of fish meat up to 8 days.

The effect of edible gelatin coating may be due to its barrier role against oxygen diffusion and thus bacterial proliferation, by forming a protein bio-film around the fish sample. Particularly, black-barred skin 
gelatin could be a potential agent for better preservation of fish fillet during chilled storage. It has been reported that gelatin hydrolysates are known by their antibacterial effect against specific spoiler organisms of chilled fish, including Shewanella putrefaciens and Photobacterium phosphoreum (Gómez-Guillén et al., 2010). As the same, Jridi et al. (2018) have shown the antibacterial effect of fish gelatin coating on the protection of meat against bacterial spoilage during cold storage. In another study, Hosseini, Rezaei, Zandi, and Ghavi (2015) coated rainbow trout fillet with fish gelatin containing oregano essential oil (bioactive molecules) and observed an enhanced reduction of psychrotrophilic bacterial counts after bioactive gelatin coating in comparison with control and gelatin-coated samples. In addition, Wu et al. (2014) demonstrated that grass carp muscle covered with fish gelatin-chitosan film containing oregano oil showed the lowest total aerobic bacteria and TVB-N values, compared to the other groups.

\section{Conclusions}

In summary, this study emphasizes the use of black-barred halfbeak gelatin enriched with its Purafect-hydrolysate in the enhancement of smooth hound fillets quality and in the delay of their spoilage during conservation at $4{ }^{\circ} \mathrm{C}$. In addition, gelatin coating helps to preserve the initial color of fresh fillets, slow the lipid and protein oxidation, microbial growth and nucleotides and proteins degradation. Moreover, BG coating was more efficient than bovine commercial gelatin, which was further improved by the addition of BGH in the gel of gelatin before fish dipping. Therefore, black-barred gelatin plays a beneficial role, as an edible coating agent, in extending the shelf life of the fish meat products.

\section{Acknowledgement}

This work was funded and financially supported by the Ministry of Higher Education and Scientific Research, Tunisia (Grant no. 18PJEC06-03).

\section{References}

Abdelhedi, O., Nasri, R., Mora, L., Toldrá, F., Nasri, M., \& Jridi, M. (2017). Collagenous proteins from black-barred halfbeak skin as a source of gelatin and bioactive peptides. Food Hydrocolloids, 70, 123-133.

Abelti, A. L. (2013). Microbiological and chemical changes of Nile Tilapia (Oreochromis niloticus L.) fillet during ice storage: Effect of age and sex. Advance Journal of Food Science and Technology, 5, 1260-1265.

Adler-Nissen, J. (1986). A review of food protein hydrolysis specific areas: Enzymic hydrolysis of food proteins. New York: Elsevier Applied Science Publications ISBN: 100853343861.

Alemán, A., González, F., Arancibia, M. Y., López-Caballero, M. E., Montero, P., \& GómezGuillén, M. C. (2016). Comparative study between film and coating packaging based on shrimp concentrate obtained from marine industrial waste for fish sausage preservation. Food Control, 70, 325-332.

Alemán, A., Pérez-Santín, E., Bordenave-Juchereau, S., Arnaudin, I., Gómez-Guillén, M. C., \& Montero, P. (2011). Squid gelatin hydrolysates with antihypertensive, anticancer and antioxidant activity. Food Research International, 44, 1044-1051.

Andevari, G. T., \& Rezaei, M. (2011). Effect of gelatin coating incorporated with cinnamon oil on the quality of fresh rainbow trout in cold storage. International Journal of Food Science and Technology, 46, 2305-2311.

Antoniewski, M. N., Barringer, S. A., Knipe, C. L., \& Zerby, H. N. (2007). Effect of a gelatin coating on the shelf life of fresh meat. Journal of Food Science, 72, 38-387.

Arancibia, M. Y., López-Caballero, M. E., Gómez-Guillén, M. C., \& Montero, P. (2015). Chitosan coatings enriched with active shrimp waste for shrimp preservation. Food Control, 54, 259-266.

Arvanitoyannis, I. S. (2002). Formation and properties of collagen and gelatin films and coatings. In A. Gennadios A (Vol. Ed.), Proteinbased films and coatings: Vol. 2002, (pp. 275-304). Boca Raton: CRC Press Lancaster EUA.

Bekhit, A. E. D., \& Faustman, C. (2005). Metmyoglobin reducing activity. Meat Science, $71,407-439$.

Benbettaïeb, N., Karbowiak, T., \& Debeaufort, F. (2017). Bioactive edible films for food applications: Influence of the bioactive compounds on film structure and properties. Critical Reviews in Food Science and Nutrition. https://doi.org/10.1080/10408398. 2017.1393384.

Cai, L., Nian, L., Cao, A., Wu, W., Wang, J., Wang, Y., et al. (2018). Effects of xylitol and stevioside on the physical and rheological properties of gelatin from cod skin. Food Science and Technology International. https://doi.org/10.1177/1082013218784389.
Chandra, M. V., \& Shamasundar, B. A. (2015). Rheological properties of gelatin prepared from the swim bladders of freshwater fish Catla catla. Food Hydrocolloids, 48, 47-54.

Das, M. P., Suguna, P. R., Prasad, K., Vijaylakshmi, J. V., \& Renuka, M. (2017). Extraction and characterization of gelatin: A functional biopolymer. International Journal of Pharmacy and Pharmaceutical Sciences, 9, 239-242.

De Oliveira, K., \& Silva, S. (2017). Effect of protein and polysaccharide-based edible coatings on quality of kiwifruit (Actinidia deliciosa) during drying. International Journal of Food Engineering, 13, 11-18.

Duan, Z., Jiang, L., Wang, J., Yu, X., \& Wang, T. (2011). Drying and quality characteristics of tilapia fish fillets dried with hot air-microwave heating. Food and Bioproducts Processing, 89, 472-476.

EC Commission Regulation (EC, No 1022/2008) of 17 october 2008 amending regulation (EC) $\mathrm{N}^{\circ} 2074 / 2005$ as regards the total volatile basic nitrogen (TVB-N) limits. Official Journal of European Union, L277, 18-20.

Esterbauer, H., Cheeseman, K. H., Dianzani, M. U., Poli, G., \& Slater, T. I. (1982) Separation and characterization of the aldehydic products of lipid peroxidation stimulated by ADP $\mathrm{Fe}^{2+}$ in rat liver microsomes. Biochemical Journal, 208, 129-140.

Fan, W., Sun, J., Chen, Y., Qiu, J., Zhang, Y., \& Chi, Y. (2009). Effects of chitosan coating on quality and shelf life of silver carp during frozen storage. Food Chemistry, 115, 66-70.

Farajzadeh, F., Motamedzadegan, A., Shahidi, S.-A., \& Hamzeh, S. (2016). The effect of chitosan-gelatin coating on the quality of shrimp (Litopenaeus vannamei) under refrigerated condition. Food Control, 67, 163-170.

Feng, X., Bansal, N., \& Yang, H. (2016). Fish gelatin combined with chitosan coating inhibits myofibril degradation of golden pomfret (Trachinotus blochii) fillet during cold storage. Food Chemistry, 200, 283-292.

Gómez-Guillén, M. C., López-Caballero, M. E., López de Lacey, A., Alemán, A., Giménez, B., \& Montero, P. (2010). Antioxidant and antimicrobial peptide fractions from squid and tuna skin gelatin. In E. Le Bihan, \& N. Koueta (Eds.). Sea by-products as a real material: New ways of application (pp. 89-115). Transworld Research NetworkSignpost.

Hernández-Cázares, A. S., Aristoy, M.-C., \& Toldrá, F. (2011). Nucleotides and their degradation products during processing of dry-cured ham, measured by HPLC and an enzyme sensor. Meat Science, 87, 125-129.

Herring, J. L., Jonnalongadda, S. C., Narayanan, V. C., \& Coleman, S. M. (2010). Oxidative stability of gelatin coated pork at refrigerated storage. Meat Science, 85 , 651-656.

Heydari, A., Alemzadeh, I., \& Vossoughi, M. (2013). Functional properties of biodegradable corn starch nanocomposites for food packaging applications. Materials \& Design, 50, 954-961.

Hosseini, S. F., \& Gómez-Guillén, M. C. (2018). A state-of-the-art review on the elaboration of fish gelatin as bioactive packaging: Special emphasis on nanotechnologybased approaches. Trends in Food Science \& Technology, 79, 125-135.

Hosseini, S. F., Rezaei, M., Zandi, M., \& Ghavi, F. F. (2015). Effect of fish gelatin coating enriched with oregano essential oil on the quality of refrigerated rainbow trout fillet. Journal of Aquatic Food Product Technology, 25, 835-842.

Huang, X., Tu, Z., Xiao, H., Wang, H., Zhang, L., Hu, Y., et al. (2012). Characteristics and antioxidant activities of ovalbumin glycated with different saccharides under heat moisture treatment. Food Research International, 48, 866-872.

International Commission on the Microbiological Specifications for Foods (ICMSF) (1986). Sampling plans for fish and shellfish: Microorganisms in foods. Sampling for microbiological analysis: Principles and scientific applications (2nd Ed). Toronto, Canada: University of Toronto Press.

Jansson, K., Haegerstrand, A., \& Kratz, G. (2001). A biodegradable bovine collagen membrane as a dermal template for human in vivo wound healing. Scandinavian Journal of Plastic and Reconstructive Surgery and Hand Surgery, 35, 369-375.

Jian, S., Wenyi, T., \& Wuyong, C. (2011). Kinetics of enzymatic unhairing by protease in leather industry. Journal of Cleaner Production, 19, 325-331.

Jridi, M., Bardaa, S., Moalla, D., Rebaii, T., Souissi, N., Sahnoun, Z., et al. (2015) Microstructure, rheological and wound healing properties of collagen-based gel from cuttlefish skin. International Journal of Biological Macromolecules, 77, 369-374.

Jridi, M., Lassoued, I., Nasri, R., Ayadi, M. A., Nasri, M., \& Souissi, N. (2014). Characterization and potential use of cuttlefish skin gelatin hydrolysates prepared by different microbial proteases. BioMed Research International, 2014. https://doi.org/ $10.1155 / 2014 / 461728$

Jridi, M., Mora, L., Souissi, N., Aristoy, M.-C., Nasri, M., \& Toldrá, F. (2018). Effects of active gelatin coated with henna ( $L$. inermis) extract on beef meat quality during chilled storage. Food Control, 84, 238-245.

Jurado, Á., García, C., Timón, M. L., \& Carrapiso, A. I. (2007). Effect of ripening time and rearing system on amino acid-related flavour compounds of Iberian ham. Meat Science, 75, 585-594.

Kakaei, S., \& Shahbazi, Y. (2016). Effect of chitosan-gelatin film incorporated with ethanolic red grape seed extract and Ziziphora clinopodioides essential oil on survival of Listeria monocytogenes and chemical, microbial and sensory properties of minced trout fillet. Lebensmittel-Wissenschaft und -Technologie- Food Science and Technology, $72,432-438$.

Lassoued, I., Mora, L., Barkia, A., Aristoy, M.-C., Nasri, M., \& Toldrá, F. (2015). Bioactive peptides identified in thornback ray skin's gelatin hydrolysates by proteases from Bacillus subtilis and Bacillus amyloliquefaciens. Journal of Proteomics, 128, 8-17.

Limpisophon, K., Tanaka, M., Weng, W. Y., Abe, S., \& Osako, K. (2009). Characterization of gelatin films prepared from under-utilized blue shark (Prionace glauca) skin. Food Hydrocolloids, 23, 1993-2000.

Lorenzo, J. M., Sarriés, M. V., Tateo, A., Polidori, P., Franco, D., \& Lanza, M. (2014). Carcass characteristics, meat quality and nutritional value of horsemeat: A review. Meat Science, 96, 1478-1488.

Marggrander, K., \& Hofmann, K. (1997). Reduction of freezer burn and loss on drying 
during long term storage of pork with gelatin spray solution. Fleischwirtschaft, 77, 19-20.

Morachis-Valdez, A. G., Gómez-Oliván, L. M., García-Argueta, I., Hernández-Navarro, M. D., Díaz-Bandera, D., \& Dublán-García, O. (2017). Effect of chitosan edible coating on the biochemical and physical characteristics of Carp fillet (Cyprinus carpio) stored at $-18^{\circ}$ C. International Journal of Food Science. https://doi.org/10.1155/2017/2812483.

Moreno, O., Atarés, L., Chiralt, A., Cruz-Romero, M. C., \& Kerry, J. (2018). Starch-gelatin antimicrobial packaging materials to extend the shelf life of chicken breast fillets. Lebensmittel-Wissenschaft und -Technologie-Food Science and Technology, 97, 483-490.

Nikoo, M., Benjakul, S., \& Xu, X. (2015). Antioxidant and cryoprotective effects of Amur sturgeon skin gelatin hydrolysate in unwashed fish mince. Food Chemistry, 181, 295-303.

Nowzari, F., Shábanpour, B., \& Ojagh, S. M. (2013). Comparison of chitosan-gelatin composite and bilayer coating and film effect on the quality of refrigerated rainbow trout. Food Chemistry, 141, 1667-1672.

Ojagh, S. M., Rezaei, M., Razavi, S. H., \& Hosseini, S. H. (2010). Effect of chitosan coatings enriched with cinnamon oil on the quality of refrigerated rainbow trout. Food Chemistry, 120, 193-198.

Özogul, F., Taylor, K. D. A., Quantick, P. C., \& Özogul, Y. (2000). A rapid HPLC-determination of ATP-related compounds and its application to herring stored under modified atmosphere. International Journal of Food Science and Technology, 35, 549-554.

Potorac, S., Popa, M., Maier, V., Lisa, G., \& Verestiuc, L. (2012). New hydrogels based on maleilated collagen with potential applications in tissue engineering. Material Science of Engeneering, 32, 236-243.

Santos, J., Lisboa, F., Pestana, N., Casal, S., Alves, M. R., \& Oliveira, M. B. P. P. (2013). Shelf life assessment of modified atmosphere packaged turbot (Psetta maxima) fillets: Evaluation of microbial, physical and chemical quality parameters. Food and Bioprocess Technology, 6, 2630-2639.

Sathivel, S. (2005). Chitosan and protein coatings affect yield, moisture loss, and lipid oxidation of pink salmon (Oncorhynchus gorbuscha) fillets during frozen storage. Journal of Food Science, 70, 455-459.
Sell, C., Beamer, S., Jaczynski, J., \& Matak, K. E. (2015). Sensory characteristics and storage quality indicators of surimi franks nutritionally enhanced with omega-3 rich flaxseed oil and salmon oil. International Journal of Food Science and Technology, 50, $210-217$.

Sinthusamran, S., Benjakul, S., Swedlund, P. J., \& Hemar, Y. (2017). Physical and rheological properties of fish gelatin gel as influenced by k-carrageenan. Food Bioscience, 20, 88-95.

Soares, N. M., Mendes, T. S., \& Vicente, A. A. (2013). Effect of chitosan-based solutions applied as edible coatings and water glazing on frozen salmon preservation - a pilotscale study. Journal of Food Engineering, 119, 316-323.

Souza, B. W. S., Cerqueira, M. A., Ruiz, H. A., Martins, J. T., Casariego, A., Teixeira, J. A. et al. (2010). Effect of chitosan-based coatings on the shelf life of salmon (Salmo salar). Journal of Agricultural and Food Chemistry, 58, 11456-11462.

Surówka, K. (1997). Effect of protein hydrolysate on the instrumental texture profile of gelatin gels. Journal of Texture Study, 28, 289-303.

Viji, P., Panda, S. K., Mohan, C. O., Bindu, J., Ravishankar, C. N., \& Srinivasa Gopal, T. K. (2016). Combined effects of vacuum packaging and mint extract treatment on the biochemical, sensory and microbial changes of chill stored Indian mackerel. Journal of Food Science \& Technology, 53, 4289-4297.

Vuorela, S., Salminen, H., Mäkelä, M., Kivikari, R., Karonen, M., \& Heinonen, M. (2005). Effect of plant phenolics on protein and lipid oxidation in cooked pork meat patties. Journal of Agricultural and Food Chemistry, 53, 8492-8497.

Wang, L., Liang, Q., Chen, T., Wang, Z., Xu, J., \& Ma, H. (2014). Characterization of collagen from the skin of Amur sturgeon (Acipenser schrenckii). Food Hydrocolloids, 38, 104-109.

Witte, V. C., Krause, G. F., \& Bailey, M. E. (1970). A new extraction method for determining 2-thiobarbituric acid values of pork and beef during storage. Journal of Food Science, 35, 582-585.

Wu, J., Ge, S., Liu, H., Wang, S., Chen, S., Wang, J., et al. (2014). Properties and antimicrobial activity of silver carp (Hypophthalmichthys molitrix) skin gelatin-chitosan films incorporated with oregano essential oil for fish preservation. Food Packaging and Shelf Life, 2, 7-16. 